Check for updates

Kent

Cite this as: BMJ 2021;375:n2948

http://dx.doi.org/10.1136/bmj.n2948

Published: 29 November 2021

\section{Recycling in the NHS-where does the buck stop?}

\author{
Natasha Varshney,
}

It was an ordinary working day at hospital and I was in the treatment room clearing up a tray I had used for cannulation. I mumbled pleasantries to our housekeeper who had come in to help with stocking up. Unfortunately, our small treatment room only had a single orange clinical waste bin, and we soon found ourselves awkwardly dancing around each other as we disposed of our respective packaging. Absentmindedly, we both threw non-contaminated packaging in the clinical waste bin, where the contents were destined for death by incineration.

It was our housekeeper who stopped mid tracks and mentioned how she wished that the packaging she was throwing away (the plastic film around blood bottle trays, plastic trays, paper slips with the medical products, etc.) could be recycled. Once I had seen this, I couldn't unsee it. It was almost as if I had been sleepwalking and I suddenly saw our use and throw habits for what they were-neglectful and careless.

Everywhere I went, I was now keenly aware of how packaging that could be recycled-if not incorrectly disposed of in the clinical waste bins-went to the black bins destined for landfill. From the cardboard boxes containing lateral flow tests to the paper wrapping around individual gauze packets, our everyday working practices are full of waste and almost none of it is recycled. When I tried to search for a recycling bin on the ward I work on I couldn't find one, and this was a commonality across the other wards I went to too.

The hospitality sector of the NHS has made huge strides in phasing out the use of single use plastics. ${ }^{1}$ Why can't this be achieved with the packaging of medical supplies? It's estimated that the NHS produces around 600000 tonnes of waste in a year-more than $1 \%$ of all domestic UK waste. ${ }^{2}$ While we don't have data on what proportion of this could have been recycled, based on personal experience I would bet this percentage is substantial.

I am unsure where the buck stops and with whom. Should our housekeeper and I have demanded that the ward have a recycling bin? Is it the responsibility of trust managers to ensure we have better recycling waste streams and to provide training on what is and isn't suitable for recycling? Is it the duty of hospital suppliers to ensure that the packaging they use is clearly marked as recyclable or non-recyclable and to strive to produce recyclable packaging if they're not using it already? Or is the onus on those in charge of services and procurement to consider whether the materials we are expected to work with come in packaging that can be recycled and to enforce better recycling streams?

In the end, I believe it is a shared responsibility. Unsustainable levels of waste and the impact it has on the environment is a problem for us all, and our solutions must be collective too. Tackling this will need both the direction and commitment of the higher echelons of the NHS, steering us on a national level, and the input of individual members of staff at a local level. Yet, currently, we on the ground need more leadership from the senior levels of the NHS, who should serve as an example and spur us on to have more environmentally friendly practices.

\footnotetext{
Competing interests: none declared.

Author's note: The recollection mention in this article is taken from when the author was a final year medical student at the University of Liverpool.

Plastic Products and Packaging. NHS Supply Chain. https://www.supplychain.nhs.uk/sustainability/plastics/

Waste in the NHS - Key Facts. BRE. https://www.bre.co.uk/page.jsp?id=2699
} 